\title{
Editorial
}

\section{¿Ley de salud social?}

La noción de enfermedad mental se emplea boy en día sobre todo para confundir y "justificar hábilmente" los problemas existentes en la relaciones personales y sociales, tal como la noción de brujería fue utilizada con el mismo fin desde comienzos de la Edad Media hasta bastante después del Renacimiento. THOMAS SZASZ

La "Ley antimaras", que hace poco salió a la luz pública, muestra rasgos que sugieren que los miembros de las pandillas se encuentran fuera del orden social por el mero hecho de pertenecer a ellas. Con ello se busca trazar una línea divisoria entre los "buenos ciudadanos" - pura y simplemente "ciudadanos"- y los "mareros". No podría entenderse de otro modo el que se considere adecuado proponer que "los que por medio de señas o 
tatuajes se identifiquen con maras o pandillas o grupos delincuenciales serán sancionados con sesenta días multa” (Art. 18). La dificultad evidente que presenta la tarea de comprobar una cierta maldad intrínseca en los sujetos que componen tales grupos se ve empequeñecida por algo más grave: tal suposición socava la base misma sobre la que se constituye el discurso contemporáneo sobre los derechos y la ciudadanía. Esta base se expresa en el argumento según el cual "todas las personas tienen un mismo valor intrínseco (...) Todo aquel que es persona es igualmente objeto de una mirada moral. Esa es la esencia de la justicia"1.

No debemos oponernos a la lógica de la "mano dura" sólo porque nos preocupen los jóvenes de las maras, sino por todos los que nos consideramos incluidos dentro de lo que podríamos llamar "comunidad ciudadana". De lo que se trata es de que, por grave que sea la falta cometida, ésta no puede ser convertida, a priori, en prueba de alguna supuesta maldad metafísica o, lo que podría ser peor, en objeto de diagnóstico psiquiátrico, clasificando al infractor de la ley como un enfermo mental al que hay que encerrar o incluso eliminar físicamente. Después de todo, la verdadera ciudadanía no es únicamente un asunto de documentos de identidad o conveniencias partidarias, sino de responsabilidades e inclusión. Sin ésta última, no es posible pensar en las primeras, por lo menos, no de tal modo que deba considerarse que todo comportamiento irresponsable excluye necesariamente de la pertenencia a la sociedad. En efecto, la ausencia de una "ciudadanía social” podría ser la causa y no el resultado de los comportamientos violentos ${ }^{2}$.

¿Significa esto que no es posible hacer nada para superar la espiral de violencia delincuencial que nos preocupa? Al contrario, de lo que se trata es de que no hacemos nada si consideramos la violencia como esencia maligna, tara genética o una especie de defecto neuronal que puede suprimirse sin sacrificar algo más que tiempo y fondos gubernamentales. Lo que nos señalan algunos estudios es que hay causas sociales, económicas y cultu- 
rales de los comportamientos antisociales, y aparejada encontramos la posibilidad del cambio conductual a través de la modificación de las condiciones de vida, el establecimiento de nuevos "reclamos sociales" y, sobre todo, la inclusión de los involucrados en actividades que proporcionen bienestar a sus mismas comunidades, a la vez que remiten a universos de sentido que ya existen en ellos: "Inclusión se refiere en su sentido más amplio a ciudadanía, a los derechos y obligaciones civiles y políticos que todos los miembros de una sociedad deberían tener, no ya formalmente, sino como una realidad en sus propias vidas".

Queremos ser enfáticos al señalar que no es correcto enfrentar el problema como si se tratase de separar lo inhumano de lo humano, como si las maras estuvieran construidas de otro modo que a partir de una trama social compleja, donde los roles y las reglas que llevan consigo nos muestran ya el rostro de lo humano y lo social. Y, tal vez, esto sea lo más difícil de aceptar: el que tengamos frente a nosotros no sólo un modo de vivir diferente sino inclusive un conjunto de usos y normas que nos cuestionan, nos interpelan y desenmascaran nuestras íntimas violencias, justo porque podemos comprender tales diferencias sólo en tanto son humanas; después de todo, tanto "ellos" como "nosotros" compartimos los modos humanos de rechazar las reglas o costumbres que nos parecen chocantes o perniciosas.

Tampoco es "moralmente correcto" recurrir maliciosamente al argumento de que quien no asume sus responsabilidades no merece ser sujeto de derechos: "Los derechos y las responsabilidades son complementarios y se necesitan mutuamente, pero, a la vez, cada uno de ellos tiene su propia situación moral que debe considerarse como parte de las relaciones basadas en fines. Una buena sociedad no niega a ninguna persona sus derechos básicos, incluso cuando no haya cumplido con sus responsabilidades, del mismo modo que no exime de responsabilidades sociales a aquellos cuyos derechos no hayan sido totalmente garantizados"4. Es un problema serio socavar la importancia del valor intrínseco de los derechos de los seres humanos, más aún 
si los interlocutores no alcanzan a ver que con ello estaríamos enterrando, probablemente, la única oportunidad que tendríamos para entablar una verdadera comunicación con aquellos que, sin compartir totalmente nuestros puntos de vista estéticos, morales o políticos, sí comparten con nosotros la única tierra habitable de la que tenemos noción: nuestra misma humanidad.

Deberíamos recordar que lo que se conoce hoy como policía tuvo en su origen una función fundamentalmente sanitaria: los guardianes del orden lo eran del orden sanitario, en tanto impedían que escaparan los que se encontraban en cuarentena o porque servían de "dique" frente a las masas indigentes y apestadas. Pero, entendámonos, estamos refiriéndonos a episodios que quedaron atrás en la historia, no al siglo XXI. Ya es hora de que dejemos los mecanismos maniqueos y supersticiosos, que pretenden encontrar relaciones intrínsecas entre las maras y las "enfermedades mentales" - puede leerse aquí drogadicción-o el culto a Satán 5 .

En esta línea podemos suscribir, como posmodernos que somos, la desconfianza radical frente a todo discurso con pretensiones de verdad absoluta o, en nuestro caso, de "salud total". Y, aunque al llevar nuestro discurso por los callejones de la discusión contemporánea sobre los derechos y la responsabilidad ciudadana, probablemente sobreestimemos a los gestores de la mentada Ley, a la vez que pasamos por alto las intenciones ocultas de su acción, no estaría mal poner en guardia una vez más contra quienes quieren suprimir la realidad de la vida humana en función de una supuesta "Idea" del bien común: "Toda realidad singular conspira contra la voluntad pura universal. Incluso aquel individuo que se encuentra ocupando la posición de la instancia normativa es contingente respecto del ideal y, por lo tanto, sospechoso (...) La supresión de la realidad por la muerte de los sospechosos consuma esta lógica que ve en la realidad un com-

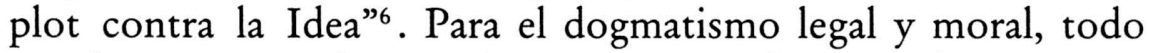
aquel que intenta hacer valer su propia reflexión sobre las normas y las reglas es sospechoso de crímenes cometidos o por 
cometer, por lo que toda previsión siempre sería poco frente al complot que se orquesta desde la realidad misma del individuo y contra el orden social.

Pero, no obstante lo anterior, en absoluto queremos sostener que toda ley deba ser suprimida ni tampoco la lógica que subyace a las normas legales. Más bien, se trata de encontrar el camino que nos las muestre históricamente, enfrentadas siempre a una exigencia de legitimación: toda ley, si quiere ser justa, deberá responder siempre ante el sujeto humano que la interpela; no desde otra ley (¿mejor?), sino, fundamentalmente, desde los proyectos concretos que surgen de lo profundo de su misma forma de vida. Y esto significa, ni más ni menos, que habrá que tener en cuenta, en primer lugar, un criterio de discernimiento para esta ley: la vida humana, en su riqueza y heterogeneidad'.

De ninguna manera debemos tratar a quien es diferente a nosotros como si fuera un sujeto enfermo, sólo porque nos parece extraño su comportamiento, porque nos repugnan sus preferencias o porque nos cuesta convivir con él. Hay mucho de miedo y cobardía en quien se apresura con la camisa de fuerza cuando lo que se espera de él es que se disponga a hablar, arriesgándose a interpelar y a ser interpelado. $¿ \mathrm{O}$ es que podemos resolver un problema sin siquiera intentar comprenderlo?

$\mathrm{Y}$, también, ¿no es necesario escuchar para comprender? Incluso a quienes se oponen a la "Ley antimaras", debemos recordarles que no escucha quien se ampara en un mero "pulso de poder", para forzar un resultado que considera correcto. Eludir el diálogo ético sobre el tema podrá ir acompañado de una intención buena en los fines particulares (oponerse a la Ley), pero radicalmente deshonesta si se mira hacia los fines más transcendentales de la comunidad política (la construcción de un proyecto político, basado en el diálogo y el consenso). No hay caminos trillados. O, como decía Hans-Georg Gadamer: "Quien comprenda tiene que comprender de otra manera, si es que quiere llegar ni siquiera a comprender"s. 
1. P. Selznick, "Social Justice: A Communitarian perspective": The Responsive Community, 6/4, otoño de 1996, p. 63.

2. Ver más adelante el artículo de Mario Lungo y Roxana Martel, "Ciudadanía social y violencia en las ciudades centroamericanas".

3. A. Giddens, The Third Way, Cambridge, Polity Press, 1998 (Las cursivas son nuestras). Ver además el trabajo de Isabel Molina, Jorge Meoni y Elena Freedman, "La experiencia de atención psicosocial en el sector San Cristóbal-San Patricio de San Salvador", que se publica en este número de la revista.

4. A. Etzioni, La Tercera Vía hacia una buena sociedad. Propuestas desde el comunitarismo, Madrid, Editorial Trotta, 2001, pp. 53-54.

5. Véase los siguientes artículos de la "Ley anti maras": "Art. 21: El que en grupo de dos o más individuos consumiere cualquier clase de substancias psicotrópicas, enervantes, alucinógenas o de cualquier otra índole en lugares públicos o abiertos al público o vías públicas o tenga en su poder cualquiera de las substancias anteriores, que por la cantidad se pueda presumir que es para su consumo, se sancionará con arresto de treinta a noventa días.

Art. 22: Los que se encuentren en los cementerios a horas nocturnas pernoctando o sin ninguna razón lícita para ello serán sancionados de diez a treinta días de arresto".

6. J-F. Lyotard, La posmodernidad (explicada a los niños), Barcelona, Editorial Gedisa, 2003, p.65.

7. Cfr. F.J. Hinkelammert, El grito del sujeto, San José, Editorial DEI, 1998.

8. H-G. Gadamer, El giro hermenéutico, Madrid, Ediciones Cátedra, 2001, p. 62. 